\title{
Discrimination on the problems of school-enterprises jointed training engineering undergraduate
}

\author{
Zhao Lijie \\ School of mechatronic engineering \\ Shenyang aerospace university \\ Shenyang, China \\ Zhaolj@sau.edu.cn
}

\author{
Yao Kai \\ School of mechatronic engineering \\ Shenyang aerospace university \\ Shenyang, China \\ 1184554759@qq.com
}

\begin{abstract}
Under the guidance of excellent engineer education and training project, this paper focus on the problems in the process of school-enterprise jointed training engineering undergraduates. The reasons based on school, enterprise, and students are presented and the measures how to solve the problems are analyzed separately. The purpose is to understand the difference between the needs of enterprises and the desire of students in order that the enterprises comply with the principle of university education and find the proper way to manage and exploit students. At the same time, the students in this project can adapt the training style as well as the requirement of university actively. Finally, the training proposal compromised between university, enterprise, and students is presented.
\end{abstract}

Keywords-excellent engineer education and training project; school-enterprise jointed training; engineering educating;

\section{INTRODUCTION}

A series of new thinking, expectation is presented in the 18th CPC National Congress. Several 'First Time' are illustrated in the report. For instance, 'Make great effort on the education to satisfy the people' illuminates prominently the people oriented thinking in the view of scientific development. 'The education is the cornerstone of ethnic promotion and social advancement' shows the important position of education in the construction of affluent society. 'Pushing forward the intension development of high level education' determines the direction of high level education scientific development in new historic era. 'Developing sense of social responsibility, innovating spirit, and practical ability' provides new intension for the Party's education policy. Since high level education in China owns the functions of training talented person, scientific research, social service, and culture heritage, it supplies the indemnification of talented person and intelligent support for our nation's modernization construction. It needs that high level education insists on the core position of people oriented consciously in order to train more and better high-quality talented person and promote the abilities of national's industrialization, informatization, urbanization, and agricultural modernization [1].

Our country is a big educational country, but it is not a strong country, especially for the high level education. The problems are emerged as follows: (1) the difference between the quality of talented person and the requirement of economic society development; (2) the difference between disciplines' structure and the requirement of Industrial restructuring; (3) the difference between Autonomous innovation ability and the requirement of international competition; (4) the difference between university's autonomous running a school and the requirement of building a modern university’s system; etc. The essential reasons are the development is not scientific and training quality is not high enough. Therefore, promoting university's quality is the lifeline. It is the most central and urgent mission of high level education reform.

In China, there is a common consensus which going to the university is for finding a good occupation. However, few students from primary school up to college know how to plan their career based on their interests. In recent years, more students like to select the occupations in government since there are the leisure status, good income, and high level social position. It is partly because it is hard to find a job for a graduate and it is induced the shortage of professional talented person at the same time. With the economic depression around the world and economy reconstruction in our country, the dilemma of employment is emerging. In the report of 'the status of employment of China's undergraduate in 2012', it shows nearly 570 thousands undergraduates are unemployed, 100 thousands undergraduates have to live with their parents. Even if the undergraduates have jobs, $47 \%$ of them show they are satisfied their jobs. Nowadays, the undergraduates have to face bad employment status, one reason is the enterprises always complain they have not practical experience; the other one is more and more students pursue high income and high level occupation and waive the opportunity of employment proactively.

In 2010, the education ministry presents the project that a large batch of high quality, innovative, and adapted the development of economy talented persons will be brought up toward the requirement of industry, world, and future. It will be aimed to build sturdy human resource superiority for our innovative country, realizing industrialization and modernization so as to enhance our country's competitive strength and national power [2-4]. In 2006, some enterprises began to take part in formulating excellent engineer education and training project and present the specific programs according to the situation of related enterprise and industry [5-6]. In 2010, Liaoning province issued 'Liaoning province medium and long term development project' and 'excellent engineer education and training project' is 
regarded as one of the 15 major projects. University and enterprise jointed training engineering undergraduate is an effective way to fulfill the mission of high level education. In this process, the related majors in university and the cooperated enterprises are connected together to share the educational and practical resources. First of all, the employment pressure can be assuaged for university. Under contract, university is able to send definite number of students to enterprise. Next, enterprise can select the proper students in advance and make the students adapt to enterprise beforehand. When the students graduate from university, the enterprise arranges them easily and properly because of their performance in enterprise. In the final, one year practice in enterprise makes the students plan their occupation in the future, promote their practical ability, and understand their major clearly. But there are some problems emerged in the process of university and enterprise jointed training engineering undergraduate, the different ideas between university and enterprise are contradicted each other and the students have to undertake dilemma situation. In this paper, these problems are discussed and the approaches are presented to solve the problems.

\section{PRoblems to BE SOLVED}

\section{A. Problems for students}

For the students taking part in excellent engineer education and training project, it should be said honored since the students can own a job offer supplied by the enterprise before they graduate. The students can enter the enterprise in the senior year and receive the fieldwork salary. Nonetheless some problems in practice arise when students entered enterprise.

Firstly, our university made a contract with one enterprise of Geely Motors in 2012 and sent 10 students to enter the enterprise as trainee. Through nearly one year practice, the outcome is some courses which are taught in the 7th semester since the students have left university, the students have to study the courses in enterprise. The effect of study is not compared favorable with the study in university.

Secondly, the students are not familiar with life in enterprise and regarded themselves as the cheap labors. In enterprise, although you are a trainee, you have to be arranged in the fixed position to practice. For this, the students lose the study interest gradually. Some time, the students have to suffer overtime work since the requirement of enterprise.

Thirdly, there are some discrepancy on working condition and income compared with the signed contract before. This maybe affects students' loyalty to enterprise.

Fourthly, some of the students didn't get the credits in some courses in former semesters, for example, physics, algebra, etc.. They have to take new exam in the final year to get the credits, although small amount of students suffer this situation.

\section{B. Problems for university}

Since it is the first time to engage the project and university is lack of the understanding to enterprise, the teaching plan to the student can not bridge the gap between university and enterprise. It is mainly reflected in the teaching plan of courses related in 7th semester. Generally, there are at least three professional courses in this semester and it is very useful to the students' future career option. Although the university has adopted a measure to send professional teacher to teach the students in the enterprise, the courses are normally to teach in short period (as shown in Fig. 1). The students can not absorb the knowledge effectively. At the same time, some practical contents should be addressed just like the curriculum designs. The students have to finish the designs in enterprise. The quality of design is hard to control since students do the design without supervising under teacher.

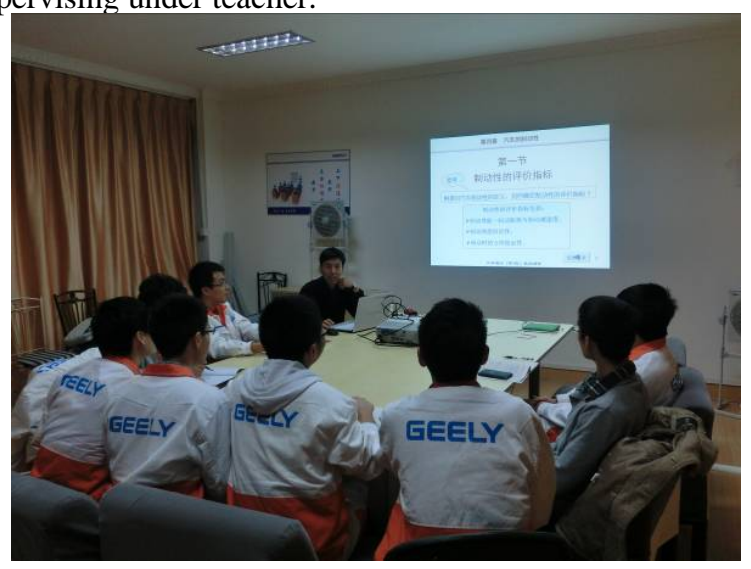

Figure 1.Teaching profesional course in enterprise.

\section{Problems for enterprise}

For the enterprise, the training system is not proper to the students of excellent engineer education and training project. No clerk can handle the affairs professionally leading to the students not coping with professional knowledge and enterprise's training effectively. In addition, some training contents supplied by the enterprise not only can not make the students understand the special process in enterprise, but also detach with the requirement of university, evenly sections of enterprise. Finally, coordination between different sections is not consistency each other, they are not able to handle trainee effectively.

\section{MEASURES TO BE APPLIED}

In fact, education and training are different completely. Training generally utilizes the known knowledge to train in order to make the trainee memorize some known skills through indoctrinating repeatedly. Education takes the same way to engraft knowledge to students, but its purpose is to teach the students to acquire the ability to probe the unknown world. Education faces lively individual other than make the individuals become the same style tool like a machine. It is the big issue to university and enterprise. Education can teach you to form positive values to the outside world, but training is never to achieve this level since there are too strongly special objectives. 


\section{A. Measures for students}

All we know the university life in our country is tough especially for engineering students. It is convinced most of students are selected to study engineering in poly-tech university for their future occupation. Normally, it is quite easier to find a job though the salary is not high comparing to the humanities. Manufacturing industry is the foundation and exemplification of one power country, so it has strong demand to undergraduates. However, with the economic depression around world since 2008 and the amount of undergraduate is increased because the policy of distensible enrollment is not suspended. In spite of these, there is strong demand to engineering students. The problem is the students how to solve the employment concept by themselves. Nowadays, the undergraduates are the outcome of china one child policy. Most of them have not brothers and their life is simple and wealthy when they grow up. They and their parents have not the preparation to undertake hard work. However, work in a manufacturing enterprise is dull and hard condition. It is normal status and a future high level engineer must be faced. It is far different from university and enterprise. Therefore, for the undergraduates, there is need to change their employment concept and adapt enterprise's life proactively. In addition, the undergraduates should abandon the idea of 'You must be one talented person if you have certain knowledge'. The idea of quick success should be waived and the level of engineering technology in a country needs down-to-earth exertion.

\section{B. Measures for university}

The contradiction of expectation between undergraduate and enterprise exist commonly in the job fairs every year. The reasons why the undergraduates are not fulfilled the requirement attract many researchers' attention and they analyzed this phenomenon. Most of them have the thought that the education system of university can not understand what kinds of undergraduates are demanded by enterprises. Firstly, the teaching plan and curriculum are too old to catch up the development of enterprise innovated technology. Enterprise is generally sensitive to up-to-date technology. Secondly, the confusion of education style on university and engineering causes the mismatch of undergraduates and enterprises. In common, the university education is far different from engineering education in Europe, for example in France and Germany. There are different education models and contents between engineer college and university, evenly the evaluation model. They can train different talented person for society and industry. University usually solves scientific issues while industry cares about solving engineering problems. However, universities in our country undertake to solve two missions at the same time. So our university needs to compromise the education model to distinguish scientific issues and engineering problems if the education system is not changed. In succession, the amount of curriculum including sequence and schedule has to be modified to adapt the excellent engineer education and training project. Thirdly, it is necessity that the university should communicate with the enterprise frequently. Comparing with university and enterprise, the students are vulnerable group. They need to accept the guidance from university. This is the unshirkable mission undertaken by university.

\section{Measures for enterprise}

For enterprises, the ability of one person is the most important factor they care when searching new employees. Although enterprise understands knowledge is not represented one person's ability, it is the prerequisite one person to have ability. Sometimes, there tend to think experience as ability, but it is a wrong idea. The undergraduates to take part in excellent engineer education and training project are not formal undergraduate and not a new clerk either. The section of human resource should formulate special schedule against them. Timetable and activities must make the undergraduates understand the function and operation of different sections in a modern manufacturing enterprise. Normally, the section of human resource in a enterprise prepare training schedule showed in Fig. 2. Through this process, the comprehension ability of undergraduates is able to be enhanced. The ability of teamwork and innovation is promoted accordingly. The perceptual knowledge to quality, purchasing, cost, and manufacturing process is achieved. At the same time, the section of human resource can organize various activities for the students in order to enrich their life in enterprise since it is part of campus life in university (as shown in Fig. 3, 4). The students are integration into enterprise and receive the culture of enterprise. One more thing is enterprise accepts the requirement of university positively and assists university to teach students under the teaching plan. Let the students acquire enough credits before they graduate.
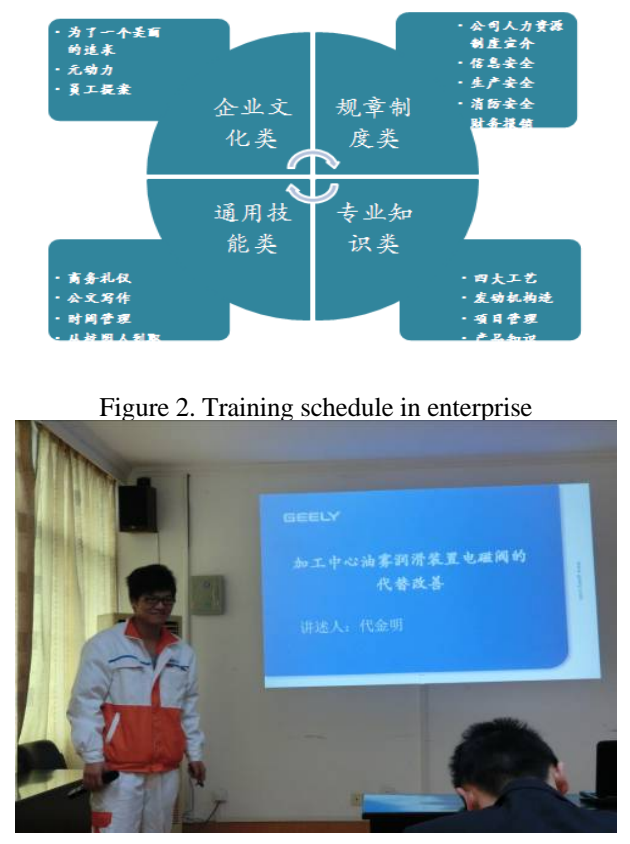

Figure 3. The student taking part in technical competition 


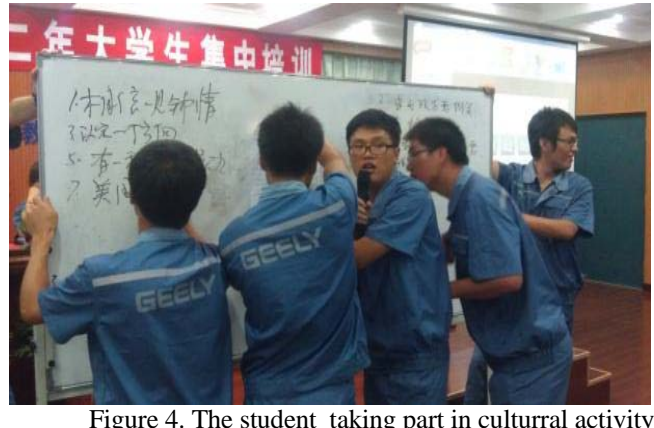

Figure 4. The student taking part in culturral activity

Above all, whether students, university, or enterprise, the education system and education manner should be reformed in order that excellent engineer education and train project can enhance the students' quality with aid of university and enterprise. This is an effective route to improve either our country manufacturing level or the employment rate of undergraduates.

\section{SUMMARY}

Excellent engineer education and training projects are derived from the demand which our country want to find the shortcut in order to enhance the development ability of engineer in manufacturing field. For this, universities and enterprises are jointed together under country's policy. They are attempting different ways to this policy and suffered many problems as well. In this paper, the problems are presented respectively and the measures of which are taken are analyzed and illustrated. The problems for the students are originated from several aspects, they are corresponded that the students are not familiar with the working modes in enterprise, shortage of self perception, unrealistic willing to enterprise, and unmet grade points of university. All these are needed the students transformed their concept of employment and face squarely present society. For the enterprise, the need of talented person is suitable to reality of education in our country and pay close attention to the potentiality of students in the future. The enterprise should be clearly distinguished between education and training. The gap of enterprise and university should be bridged proactively. It will add one piece of thinking in the construction of enterprise culture that is how to make students understand enterprise as soon as possible. For the university, it is necessary to modify the teaching plan so as that it is fulfill the requirements of excellent engineer education and training project. The university should provide a proper platform to connect enterprises and students and act as a good character of media. Through practice of one year and the collected ideas from enterprises and students, it is convinced that necessary reform of education system needs to be taken in the future comparing to advanced engineering education in Europe. Under the big background of economy reconstruction in China, certain change of engineering education will emerge soon after. The proper methods compromised university, enterprise, and undergraduate should be found to improve the engineering level and ability of undergraduates.

\section{ACKNOWLEDGMENT}

This paper is formulated under the project fund of education reform supported by department of education of Liaoning province. Geely Royo Engine Company including the undergraduates as trainee, Research Institute of Great Wall Motors, and Brilliance Automotive Engineering Research Institute supplied strong support to this project. It is grateful to thank above all.

\section{REFERENCES}

[1] P. G. Li, X. D. Xu, G. S. Chen, "On Practical Teaching of Undergraduate Engineering Education in China: Problems and Causes," Research in Higher Education of Engineering, No. 3, 2012, pp. 1-6.

[2] B. X.. Wang, "Reflections on the Carrying out of the Plan for Producing Excellent Engineer," Journal of High Education Management, Vo. 6, No. 1, 2012, pp. 15-19.

[3] B. C. Liu, "Creative Talents Training and Undergraduate Research in American Universities," Studies in Foreign Education, Vol. 32, No. 12, 2005, pp.39-43.

[4] L. J. Zhao, Y. H. Yang, "Investigation of the Exploration and Execution on the School-Enterprise Jointed Training Engineering Student," Chinese Journal of out-of-school education, No. 11, 2012, pp. 136-137

[5] H. Q. Zhao, B. L. Guo, D. F. Zhao, B. Zhang, "Investigations of Overseas Cooperative Education of Production and Learning for China's Implementation of the Plan of Cultivating Excellent Engineer, ”Value Engineering, No. 4, 2010, pp.49-52.

[6] Y. Wang, J. F. Li, "Discuss to Bring up Excellent Engineer of Mechanical Specialty," Modern Manufacturing Technology and Equipment, No. 6, 2010, pp. 69-70. 